\title{
Location-Specific Fungicide Resistance Profiles and Evidence for Stepwise Accumulation of Resistance in Botrytis cinerea
}

\begin{abstract}
Xingpeng Li, School of Agricultural, Forest, \& Environmental Sciences, Clemson University, Clemson SC 29634; Dolores FernándezOrtuño, School of Agricultural, Forest, \& Environmental Sciences, Clemson University and Instituto de Hortofruticultura Subtropical y Mediterránea "La Mayora"-Universidad de Málaga-Consejo Superior de Investigaciones Científica (IHSM-UMA-CSIC), Dept. de Microbiología, Campus de Teatinos, 29071 Málaga, Spain; Shuning Chen, Department of Plant Pathology, College of Plant Science and Technology and the Key Lab of Crop Disease Monitoring \& Safety Control in Hubei Province, Huazhong Agricultural University, Wuhan, 430070, China; Anja Grabke, School of Agricultural, Forest, \& Environmental Sciences, Clemson University; Chao-Xi Luo, Department of Plant Pathology, College of Plant Science and Technology and the Key Lab of Crop Disease Monitoring \& Safety Control in Hubei Province, Huazhong Agricultural University; William C. Bridges, Department of Mathematical Sciences, Clemson University; and Guido Schnabel, School of Agricultural, Forest, \& Environmental Sciences, Clemson University
\end{abstract}

\begin{abstract}
Li, X., Fernández-Ortuño, D., Chen, S., Grabke, A., Luo, C.-X., Bridges, W. C., and Schnabel, G. 2014. Location-specific fungicide resistance profiles and evidence for stepwise accumulation of resistance in Botrytis cinerea. Plant Dis. 98:1066-1074.

The fungicide resistance profiles to seven chemical classes of fungicides were investigated in 198 Botrytis cinerea isolates from five blackberry fields and $214 \mathrm{~B}$. cinerea isolates from 10 strawberry fields of North and South Carolina. Populations of B. cinerea tended to have a single dominant, location-specific resistance profile that consisted of resistance to multiple fungicides in fields sprayed weekly with sitespecific fungicides. The most prevalent profile in blackberry fields consisted of resistance to thiophanate-methyl, pyraclostrobin, and boscalid. The most prevalent resistance profile found in conventional strawberry fields consisted of resistance to thiophanate-methyl, pyraclostrobin, boscalid, and cyprodinil. A statistical model revealed that multifungicide resistance patterns did not evolve randomly in populations from both crops. Instead, strains resistant to thiophanate-methyl were more likely to acquire resistance to pyraclostrobin, the resulting dual-resistant population was more likely to acquire resistance to boscalid, the resulting triple-resistant population was more likely to acquire resistance to cyprodinil, and the resulting quadruple-resistant population was more likely to acquire resistance to fenhexamid (strawberry population only) compared with random chance. Resistance to

fungicide resistance profiles. Resistance to thiophanate-methyl, pyraclostrobin, boscalid, and fenhexamid in blackberry isolates was, without exception, based on target gene mutations, including E198A and E198V in $\beta$-tubulin, G143A in cytochrome b, H272Y and H272R in SdhB, and F412I in Erg27, respectively. A new genotype associated with fenhexamid resistance was found in one strain (i.e., Y408H and deletion of P298). Fungicide-resistant strains were present but rare in an unsprayed blackberry field, where some unique phenotypes, including low and medium resistance to fludioxonil, had emerged in the absence of fungicide pressure. The isolates resistant to fludioxonil had effective dose that inhibited $50 \%$ of mycelial growth values of $0.16 \mu \mathrm{g} / \mathrm{ml}$ (low resistance) and 0.32 and $0.38 \mu \mathrm{g} / \mathrm{ml}$ (medium resistance) and were also resistant to the anilinopyrimidine fungicide cyprodinil, indicating that this and similar phenotypes will eventually be selected by continued applications of the fludioxonil + cyprodinil premixture Switch. This study shows that multifungicide-resistant phenotypes are common in conventionally maintained strawberry and blackberry fields and that resistance to multiple fungicides evolved from stepwise accumulation of single resistances.
\end{abstract} iprodione and fludioxonil evolved from a pool of strains with different
Gray mold is one of the most economically important diseases of commercially produced blackberry and strawberry fruit. In the southeastern United States, the disease is caused by Botrytis cinerea Pers. and B. caroliniana X.P. Li \& G. Schnabel, a species that has only recently been reported in North and South Carolina blackberry fields $(26,32)$ and a North Carolina strawberry field (16). B. cinerea can affect yield in different ways. The pathogen may cause blight on leaf or petal tissues, crown rot, stem cankers, cutting rot, and damping-off $(9,26)$. The fungus produces germ tubes from conidia that can infect through natural openings or wounds. It is a cool-season disease and infection is favored under wet conditions with temperatures below $22^{\circ} \mathrm{C}(26,37)$. In addition to actively causing disease during the growing season, the fungus is also able to cause latent infections leading to disease after har-

Corresponding author: G. Schnabel, E-mail: schnabe@ clemson.edu

Technical contribution number 6267 of the Clemson University Experiment Station.

Accepted for publication 6 March 2014.

http://dx.doi.org/10.1094/PDIS-10-13-1019-RE

(C) 2014 The American Phytopathological Society vest, either during storage or transit, in the store, or after purchase by the consumer $(25,38,42)$.

Seven classes of site-specific fungicides are currently available for the control of gray mold disease in the United States. They include anilinopyrimidines (APs), dicarboximides (DCs), hydroxyanilides (HAs), methyl benzimidazole carbamates (MBCs), phenylpyrroles (PPs), quinone outside inhibitors (QoIs; disease suppression only), and succinate dehydrogenase inhibitors (SDHIs). Among these site-specific fungicides, MBCs were introduced in the 1970s and, therefore, have been used for the longest period of time compared with the other six site-specific fungicides mentioned above. The DCs were also introduced in the 1970s but usage dropped after the United States Environmental Protection Agency decided in 1999 to drastically limit the maximum number of applications allowed because of concerns about dietary exposure. A survey among growers in the Carolinas revealed that most had not used DCs at all over the last decade. The first QoI, SDHI, AP, and HA fungicides were registered within 1 to 4 years of each other in the United States: in 2001, 2003, 2001, and 1999 for disease control of strawberry and 2001, 2003, 2003, and 2002 for disease control of blackberry, respectively (2). Although most active ingredients are sold as solo products, some are sold as mixtures. For example, the QoI pyraclostrobin and the SDHI boscalid are sold as Pristine $38 \mathrm{WG}$ (BASF Corporation) or the AP cyprodinil and the PP fludioxonil are sold as Switch 62.5 WG (Syngenta Crop Protec- 
tion, Inc.). Most conventional growers use several different chemical classes of fungicides during the season in mixtures or rotations for resistance management. The use of multiple fungicide products over time, however, may produce pathogen populations with multifungicide resistance $(1,29,43)$. Some isolates recovered from strawberry in Germany and France exhibited multifungicide resistance in the form of ATP-binding cassette (ABC) transporter and major facilitator superfamily (MFS) transporter activity (28). However, in the southeastern United States, resistance to many fungicide classes, including the MBCs, QoIs, SDHIs, and HAs, is based on target gene alterations $(1,14,17,22)$. The objective of this study was to investigate phenotypic and evolutionary patterns of multifungicide resistance in $B$. cinerea isolates collected from commercial blackberry and strawberry farms in the Carolinas.

\section{Materials and Methods}

Origin of isolates and conidia production. Single-spore isolates of B. cinerea were obtained from decayed blackberry (198 isolates) and strawberry (214 isolates) fruit in 2010 and 2011. Isolates were either verified to be $B$. cinerea in a previous study (31) or as part of this study using cultural and molecular methods. The blackberry samples were collected from five commercial fields in Oconee (isolate code CB), Pickens (isolate code WM), Chesterfield (isolate code MC), and Chesnee (isolate code CO) Counties in South Carolina, and Cleveland County (isolate code KC) in North Carolina. The strawberry samples were collected from different commercial strawberry fields encoded HP, MV, NC, and SBY of North Carolina and FLOR, GIK, JEY, KUD, MOD, and WIC of South Carolina. All but one blackberry field (CB) had received fungicide applications in years prior to sampling. Growers from locations $\mathrm{CO}, \mathrm{KC}$, and $\mathrm{MC}$ used $\mathrm{MBC}$, QoI, SDHI, AP, and $\mathrm{HA}$ fungicides in rotation or as a mixture on a weekly schedule, making an average of over 12 applications per season. None of the growers interviewed had used DCs over the last decade. Growers from locations in WM sprayed only occasionally prior to rain events and used less than five applications, on average, per season. Weekly applications of site-specific fungicides were conducted at strawberry locations GIK, JEY, KUD, MOD, and SBY. The spray history from location NC is not known but locations FLOR, HP, and MV only received occasional fungicide treatments (less than five per season). Location WIC only received fungicides approved for organic strawberry production. We previously characterized the isolates from strawberry for resistance to APs, HAs, MBCs, QoI, PPs, and SDHIs $(14,15,17,21)$ but their multifungicide-resistant phenotypes are reported here for the first time.

For conidia production, all isolates were grown on potato dextrose agar medium (PDA; Difco Laboratories) in 9-cm-diameter petri dishes for 1 to 2 weeks at $22^{\circ} \mathrm{C}$ with 12 -h intervals of fluorescent light and darkness. Conidia were gently scraped from the colonies without touching the agar with a sterile, disposable $10-\mu 1$ inoculation loop (VWR international LLC). Conidia were then suspended in $1 \mathrm{ml}$ of sterile distilled water, and adjusted to 1 to $5 \times$ $10^{4}$ spores/ml up to $2 \mathrm{~h}$ prior to use.

Sensitivity of $B$. cinerea isolates from blackberry to cyprodinil, iprodione, fenhexamid, thiophanate-methyl, fludioxonil, pyraclostrobin, and boscalid. The following active ingredients were obtained as formulated products: AP fungicide cyprodinil (Vangard WG; Syngenta Crop Protection), DC fungicide iprodione (Roval 4 FL; Bayer CropSciences), HA fungicide fenhexamid (Elevate 50 WDG; Arysta LifeScience), MBC fungicide thiophanate-methyl (Topsin M $70 \mathrm{WP}$; Ceraxagri), PP fungicide fludioxonil (Scholar SC; Syngenta), QoI fungicide pyraclostrobin (Cabrio EG, $20 \% \mathrm{wt} / \mathrm{wt}$; BASF Corporation), and SDHI fungicide boscalid (Endura 70\% wt/wt; BASF). Sensitivity was assessed using a previously published germination assay (44) that evaluates fungicide sensitivity based on spore germination on a medium amended with discriminatory doses of fungicides. The experiments were repeated once. Germination was assessed visually under a light microscope (Olympus BX41TF; Olympus Optical Co. Ltd.). There were 12 isolates that germinated with iprodione at $5 \mu \mathrm{g} / \mathrm{ml}$ but were unable to germinate at $50 \mu \mathrm{g} / \mathrm{ml}$. This phenotype was not described by Weber and Hahn and was described in this study as low-resistant (LR). The LR and sensitive phenotypes for iprodione were merged in Tables 1 and 2 for simplicity reasons because the LR phenotype has not been associated with field resistance. The distinction between medium resistance (MR) and low resistance to fludioxonil was based on differences in germination at the two discriminatory doses of fludioxonil of 0.1 and $10 \mu \mathrm{g} / \mathrm{ml}$ (44). Isolates were assigned to the LR category if germ tube growth exceeded $60 \%$ at $0.1 \mu \mathrm{g} / \mathrm{ml}$ and $5 \%$ at $10 \mu \mathrm{g} / \mathrm{ml}$ compared with the nonfungicidetreated control. For the DC and PP groups, where there is no discontinuity in the sensitivity distribution, experimental evidence

Table 1. Phenotypic variation in fungicide resistance of Botrytis cinerea isolates from blackberry and strawberry fields in South Carolina and North Carolina

\begin{tabular}{|c|c|c|c|c|c|c|c|c|c|c|c|c|c|c|c|c|c|c|}
\hline \multirow[b]{3}{*}{ Phenotype $^{\text {b }}$} & \multirow[b]{3}{*}{ SRs ${ }^{c}$} & \multicolumn{15}{|c|}{ Number of isolates ${ }^{a}$} & \multirow[b]{3}{*}{${ }^{2}$ Total } & \multirow[b]{3}{*}{$\%$} \\
\hline & & \multicolumn{5}{|c|}{ Blackberry field } & \multicolumn{10}{|c|}{ Strawberry field } & & \\
\hline & & $\mathrm{CB}^{0}$ & $\mathrm{WM}^{<5}$ & $K C^{>12}$ & $\mathrm{MC}^{>12}$ & $\mathrm{CO}^{>12}$ & WIC $^{0}$ & $\mathrm{MV}^{<5}$ & $\mathrm{HP}^{<5}$ & $\mathrm{FLOR}^{<5}$ & $\mathrm{NC}^{\mathrm{N} / \mathrm{A}}$ & GIK $^{>12}$ & ${ }^{2} \mathrm{MOD}^{>12}$ & ${ }^{2} \mathrm{SBY}^{>12}$ & $\mathrm{JEY}>12$ & ${ }^{2} \mathrm{KUD}^{>12}$ & & \\
\hline 1, None & OSR & 51 & 4 & 1 & 0 & 0 & 8 & 8 & 29 & 10 & 5 & 3 & 2 & 0 & 0 & 0 & 121 & 29.37 \\
\hline 2, Py & $1 \mathrm{SR}$ & 1 & 0 & 0 & 0 & 0 & 0 & 0 & 0 & 0 & 0 & 0 & 0 & 0 & 0 & 0 & 1 & 0.24 \\
\hline $3, \mathrm{Tm}$ & $1 \mathrm{SR}$ & 0 & 24 & 0 & 0 & 0 & 0 & 0 & 3 & 0 & 0 & 1 & 0 & 0 & 0 & 0 & 28 & 6.80 \\
\hline 4, Tm-Bo & $2 \mathrm{SR}$ & 0 & 1 & 0 & 0 & 0 & 0 & 0 & 0 & 0 & 0 & 0 & 0 & 0 & 0 & 0 & 1 & 0.24 \\
\hline 5, Tm-Cy & $2 \mathrm{SR}$ & 0 & 0 & 0 & 0 & 0 & 2 & 0 & 0 & 0 & 0 & 1 & 0 & 0 & 0 & 0 & 3 & 0.73 \\
\hline 6, Tm-Py & $2 \mathrm{SR}$ & 0 & 2 & 1 & 0 & 0 & 3 & 0 & 0 & 0 & 0 & 2 & 0 & 1 & 0 & 0 & 9 & 2.18 \\
\hline 7, Tm-Ip-Fl & $3 \mathrm{SR}$ & 1 & 0 & 0 & 0 & 0 & 0 & 0 & 0 & 0 & 0 & 0 & 0 & 0 & 0 & 0 & 1 & 0.24 \\
\hline 8, Tm-Рy-Bo & $3 \mathrm{SR}$ & 0 & 7 & 33 & 3 & 19 & 2 & 1 & 0 & 1 & 0 & 6 & 3 & 3 & 2 & 8 & 88 & 21.36 \\
\hline 9, Тm-Рy-Сy & $3 \mathrm{SR}$ & 0 & 0 & 0 & 0 & 0 & 0 & 0 & 0 & 0 & 0 & 0 & 2 & 1 & 0 & 0 & 3 & 0.73 \\
\hline 10, Tm-Py-Fe & $3 \mathrm{SR}$ & 0 & 1 & 0 & 0 & 0 & 0 & 0 & 0 & 0 & 0 & 0 & 0 & 0 & 0 & 0 & 1 & 0.24 \\
\hline 11, Tm-Py-Bo-Cy & $4 \mathrm{SR}$ & 0 & 0 & 0 & 4 & 8 & 6 & 2 & 0 & 2 & 3 & 5 & 8 & 11 & 18 & 12 & 79 & 19.17 \\
\hline 12, Tm-Py-Bo-Fe & $4 \mathrm{SR}$ & 0 & 1 & 14 & 0 & 4 & 0 & 0 & 0 & 0 & 1 & 0 & 0 & 8 & 1 & 1 & 30 & 7.28 \\
\hline 13, Tm-Py-Bo-Ip & $4 \mathrm{SR}$ & 0 & 1 & 0 & 7 & 3 & 0 & 0 & 0 & 0 & 0 & 0 & 0 & 1 & 0 & 0 & 12 & 2.91 \\
\hline 14, Тm-Рy-Во-Су-Iр & $5 \mathrm{SR}$ & 0 & 1 & 0 & 1 & 0 & 0 & 0 & 0 & 0 & 0 & 0 & 0 & 1 & 2 & 0 & 5 & 1.21 \\
\hline 15, Tm-Py-Bo-Ip-Fe & $5 \mathrm{SR}$ & 0 & 0 & 0 & 1 & 0 & 0 & 0 & 0 & 0 & 0 & 0 & 0 & 0 & 0 & 0 & 1 & 0.24 \\
\hline 16, Tm-Рy-Во-Су-Fe & $5 \mathrm{SR}$ & 0 & 0 & 2 & 0 & 0 & 0 & 0 & 1 & 0 & 3 & 3 & 5 & 11 & 2 & 0 & 27 & 6.55 \\
\hline 17, Tm-Py-Cy-Ip-Fl & $5 \mathrm{SR}$ & 0 & 0 & 2 & 0 & 0 & 0 & 0 & 0 & 0 & 0 & 0 & 0 & 0 & 0 & 0 & 2 & 0.49 \\
\hline Total & $\ldots$ & 53 & 42 & 53 & 16 & 34 & 21 & 11 & 33 & 13 & 12 & 21 & 20 & 37 & 25 & 21 & 412 & 100.00 \\
\hline
\end{tabular}

a Numbers in superscript following field names indicate the estimated number of sprays with site-specific fungicide per season. Number of isolates of a majority phenotype is displayed in bold.

${ }^{\mathrm{b}}$ Phenotype number and resistance to fungicides Py = pyraclostrobin (quinone outside inhibitor), Tm = thiophanate methyl (methyl benzimidazole carbamate), Bo = boscalid (succinate dehydrogenase inhibitor), $\mathrm{Cy}=$ cyprodinil (anilinopyrimidine), $\mathrm{Ip}=$ iprodione (dicarboximide), $\mathrm{Fl}=$ fludioxonil (phenylpyrrole), $\mathrm{Fe}=$ fenhexamid (hydroxyanilide).

c Single resistances. 
was provided recently that the "resistant" isolates are pathogenic on fruit treated with field rates of formulated product (21).

The effective doses that inhibit $50 \%$ of mycelial growth $\left(\mathrm{EC}_{50}\right.$ values) were investigated in vitro for fludioxonil as described previously (28), with minor modifications. Briefly, 5,000 spores were transferred to $0.1 \mathrm{ml}$ of malt extract broth containing a series of dilutions of fungicides in a 96-well microplate. Final concentrations for all compounds were $10,3,1,0.3,0.1,0.03,0.01$, and 0 $\mu \mathrm{g} / \mathrm{ml}$. After $48 \mathrm{~h}$ of incubation at $22^{\circ} \mathrm{C}$ in darkness, the optical density at wavelength $A_{600}$ was determined. The experiment was performed twice.

Molecular identification of point mutations in target genes erg 27, sdhB, cytochrome $b$, and $\beta$-tubulin. Nucleic acid sequence alterations in the strawberry isolates associated with the here-described resistance phenotypes were reported previously $(14,17,22)$. Sequence alterations in target genes of $B$. cinerea isolates from blackberry were assessed in this study. Isolates were cultured on PDA plates at $22^{\circ} \mathrm{C}$ in darkness. Mycelia were collected from the developing margin of an actively growing colony using a sterile toothpick. Genomic DNA was extracted as described previously (8). The partial 3-keto reductase gene (erg27) was amplified and sequenced with primer pair F412_F and F412_R (22). The entire $\operatorname{erg} 27$ gene of isolate KC52 was amplified with primer pair erg27Beg and erg27End because sequence analysis of the fragment amplified with primers F42_F and F412_R did not show the suspected F412 mutations. Sequencing was conducted with primers erg27Beg, erg27End, erg1800down, and erg2000up (19).

Point mutations in the succinate dehydrogenase $\mathrm{B}(s d h \mathrm{~B})$ gene were identified as described previously with primer pair IpBcBeg and IpBcEnd2 (30), with minor modifications of the polymerase chain reaction (PCR) protocol. The initial denaturation was at $95^{\circ} \mathrm{C}$ for $3 \mathrm{~min}$; followed by 35 cycles at $95^{\circ} \mathrm{C}$ for $30 \mathrm{~s}, 58^{\circ} \mathrm{C}$ for $30 \mathrm{~s}$, and $72^{\circ} \mathrm{C}$ for $1 \mathrm{~min}$; and a final extension at $72^{\circ} \mathrm{C}$ for $10 \mathrm{~min}$. The PCR products were purified using the ExoSAP-IT PCR purification kit (USB Corporation) following the manufacturer's instructions and sequenced at the Clemson University Genomics Institute, Clemson, SC using LiCOR dye-terminator sequencing technology.

Nucleotide sequence variation at amino acid codon 143 of the cytochrome $\mathrm{b}$ gene (cytb) was detected as described previously using the primer pair Qo13ext and Qo14ext (30). The amplicon was digested with restriction enzyme Fnu4HI (New England Biolabs) at $37^{\circ} \mathrm{C}$ for $2 \mathrm{~h}$. The nucleotide variation at amino acid codon198 of the $\beta$-tubulin gene was identified as described previously $(17,33)$. The partial $\beta$-tubulin gene was amplified with primer pair BCF/BCR (33) and the amplicon was digested with Tha I (New England Biolabs) at $60^{\circ} \mathrm{C}$ for $3 \mathrm{~h}$. The PCR products were sequenced if the digestion did not reveal the expected fragments. Amplicons were purified prior to sequencing using the Ex-
oSAP-IT PCR purification kit (USB Corporation) following the manufacturer's instructions. All PCR amplification or digestion products mentioned above were separated on $1.5 \%$ agarose gels.

Data analysis. Statistical analysis was performed to determine if the probability of resistance $\left(\mathrm{P}(\mathrm{R})_{\mathrm{R}}\right)$ to a fungicide in subpopulations, which were derived from a previous resistant $(\mathrm{R})$ population, differed from the probability of resistance in the overall population $\left(\mathrm{P}(\mathrm{R})_{\mathrm{E}}\right)$. A $\chi^{2}$ test was used to test the hypothesis $\mathrm{H}_{0}: \mathrm{P}(\mathrm{R})_{\mathrm{R}}=$ $\mathrm{P}(\mathrm{R})_{\mathrm{E}}$. Not included in this analysis were observations for fungicides fludioxonil and iprodione because of the low numbers of representative isolates. For all other fungicides, if less than 10 isolates represented a subpopulation, the Fisher's exact test was conducted to verify the $\chi^{2}$ result. All calculations were performed by SAS (version 8.01; SAS Institute Inc.); a $\chi^{2}$ test $P$ value $<0.05$ was considered evidence of significant differences in the $P(R)$.

\section{Results}

Fungicide resistance profiles of $B$. cinerea isolates from blackberry and strawberry fields. In total, 17 different fungicide resistance profiles containing zero to five single-resistance phenotypes (OSR to 5SR) were found in blackberry and strawberry fields of North and South Carolina; 15 phenotypes were present in blackberry fields and 11 in strawberry fields (Table 1). All but one location had a predominant resistance profile. For blackberry fields, the majority of isolates in the unsprayed field CB were sensitive to all fungicides and the majority of isolates from occasionally treated field WM were resistant to thiophanate-methyl. In all other locations, a majority of the isolates were resistant to at least three chemical classes: thiophanate-methyl, pyraclostrobin, and boscalid. A similar pattern emerged from the strawberry fields. The majority of isolates from the organic farm W/C and from fields sprayed less than six times per season were sensitive to all of the fungicides. However, the majority of isolates from most fields sprayed weekly were resistant to four chemical classes of fungicides: thiophanatemethyl, pyraclostrobin, boscalid, and cyprodinil. The two most heavily sprayed strawberry fields were located within $1 \mathrm{~km}$ of each other (SBY and MOD) and isolates from these fields had the greatest number of isolates resistant to five fungicides. Interestingly, isolates with resistance to fungicides were found in the organic field WIC, which was geographically isolated (at least $5 \mathrm{~km}$ from the next strawberry field) from other strawberry or blackberry fields. Two isolates from heavily sprayed, commercial field $\mathrm{KC}$ had a very unique phenotype not found anywhere else; they were resistant to thiophanate-methyl, pyraclostrobin, cyprodinil, iprodione, and fludioxonil. However, from the same location, the two isolates resistant to fludioxonil were genetically different based on nucleotide sequence variations in the $\mathrm{mrr} 1$, bos 2 , and $\mathrm{rrg}-1$ genes (data not shown). Iprodione-MR isolates were only found in the JEY and SBY locations (Table 1).

Table 2. Fungicide-resistant phenotypes in North and South Carolina blackberry fields

\begin{tabular}{|c|c|c|c|c|c|c|c|c|c|}
\hline \multicolumn{2}{|l|}{ Isolates } & \multirow[b]{2}{*}{$\mathbf{S R s}^{\mathbf{b}}$} & \multicolumn{7}{|c|}{ Phenotype $^{a}$} \\
\hline Number & Percent & & $\mathbf{T m}$ & Py & Bo & $\mathrm{Cy}$ & $\mathrm{Fe}$ & Ip & Fl \\
\hline 56 & 28.3 & OSR & $\mathrm{S}$ & $\mathrm{S}$ & $\mathrm{S}$ & $S$ & $\mathrm{~S}$ & $\mathrm{~S}$ & $\mathrm{~S}$ \\
\hline 1 & 0.5 & $1 \mathrm{SR}$ & $\mathrm{S}$ & $\mathbf{R}$ & S & S & S & $S$ & $\mathrm{~S}$ \\
\hline 24 & 12.1 & $1 \mathrm{SR}$ & $\mathbf{R}$ & $\mathrm{S}$ & $\mathrm{S}$ & $\mathrm{S}$ & $\mathrm{S}$ & $\mathrm{S}$ & $\mathrm{S}$ \\
\hline 1 & 0.5 & $3 \mathrm{SR}$ & $\mathbf{R}$ & $\mathrm{S}$ & S & $\mathrm{S}$ & S & $\mathbf{R}$ & LR \\
\hline 1 & 0.5 & $2 \mathrm{SR}$ & $\mathbf{R}$ & S & $\mathbf{R}$ & S & S & $S$ & S \\
\hline 3 & 1.5 & $2 \mathrm{SR}$ & $\mathbf{R}$ & $\mathbf{R}$ & S & $S$ & $\mathrm{~S}$ & S/LR & S \\
\hline 1 & 0.5 & $3 \mathrm{SR}$ & $\mathbf{R}$ & $\mathbf{R}$ & S & S & $\mathbf{R}$ & S & S \\
\hline 2 & 1.0 & $5 \mathrm{SR}$ & $\mathbf{R}$ & $\mathbf{R}$ & $\mathrm{S}$ & $\mathbf{R}$ & $\mathrm{S}$ & $\mathbf{R}$ & MR \\
\hline 70 & 35.4 & $3 \mathrm{SR}$ & $\mathbf{R}$ & $\mathbf{R}$ & $\mathbf{R}$ & S & S & S/LR & $S$ \\
\hline 21 & 10.6 & $4 \mathrm{SR}$ & $\mathbf{R}$ & $\mathbf{R}$ & $\mathbf{R}$ & $\mathrm{S}$ & $\mathbf{R}$ & S/LR & $\mathrm{S}$ \\
\hline 2 & 1.0 & $4 \mathrm{SR}$ & $\mathbf{R}$ & $\mathbf{R}$ & $\mathbf{R}$ & $S$ & $\mathrm{~S}$ & $\mathbf{R}$ & $\mathrm{S}$ \\
\hline 14 & 7.1 & $4 \mathrm{SR}$ & $\mathbf{R}$ & $\mathbf{R}$ & $\mathbf{R}$ & $\mathbf{R}$ & $\mathrm{S}$ & S/LR & S \\
\hline 2 & 1.0 & $5 \mathrm{SR}$ & $\mathbf{R}$ & $\mathbf{R}$ & $\mathbf{R}$ & $\mathbf{R}$ & $\mathbf{R}$ & S/LR & $\mathrm{S}$ \\
\hline
\end{tabular}

${ }^{\mathrm{a}} \mathrm{Tm}=$ thiophanate methyl (methyl benzimidazole carbamate), Py = pyraclostrobin (quinone outside inhibitor), Bo = boscalid (succinate dehydrogenase inhibitor), $\mathrm{Cy}=$ cyprodinil (anilinopyrimidine), $\mathrm{Fe}=$ fenhexamid (hydroxyanilide), $\mathrm{Ip}=$ iprodione (dicarboximide), $\mathrm{Fl}=$ fludioxonil (phenylpyrrole); $\mathrm{S}=$ sensitive, $\mathrm{R}=$ resistant, $\mathrm{LR}=$ low resistant, $\mathrm{MR}=$ medium resistant. Some letters are in bold for easier visualization.

b Single resistances. 
Of the 198 blackberry field isolates collected from five locations in the Carolinas, 141 (72\%) were resistant to thiophanate-methyl, $116(59 \%)$ were resistant to pyraclostrobin, $110(56 \%)$ were resistant to boscalid, 24 (12\%) were resistant to fenhexamid, 18 (9\%) were resistant to cyprodinil, $5(2.5 \%)$ were resistant to iprodione (excluding LR isolates), and 3 (1\%) were resistant to fludioxonil (2 from field $\mathrm{KC}$ were MR and one from field CB was LR; Table 1). A majority of the blackberry isolates resistant to more than two fungicides was from three commercial fields: $\mathrm{CO}, \mathrm{KC}$, and $\mathrm{MC}$ (Fig. 1). Of these isolates, $36.3 \%$ were resistant to three classes, and $18.7 \%$ were resistant to four classes of fungicides (Table 2). All other isolates from blackberry resistant to at least one fungicide were resistant to one $(13 \%)$, two $(2 \%)$, and five $(2 \%)$ classes of fungicides.

Of the 214 strawberry field isolates, 149 (70\%) were resistant to thiophanate-methyl, $142(66 \%)$ were resistant to pyraclostrobin, $133(62 \%)$ were resistant to boscalid, $46(22 \%)$ were resistant to fenhexamid, $101(47 \%)$ were resistant to cyprodinil, and $4(2 \%)$ were resistant to iprodione (Table 3). The majority of resistant isolates from strawberry possessed resistance to three or more fungicide classes $(13.5,36.9$, and $13.1 \%$ were resistant to three, four, and five classes, respectively). Most of these were from commercial fields SBY, JEY, and KUD, all located at the border of North and South Carolina, which also possessed the highest frequency of multifungicide resistance. The lowest frequencies of multifungicide-resistant isolates were observed in locations HP, MV, and FLOR (Fig. 2).

Among the isolates resistant to three fungicides, 97.2 and $89.7 \%$ of the blackberry and strawberry isolates, respectively, were resistant to thiophanate-methyl, pyraclostrobin, and boscalid. Among isolates resistant to four fungicides, more than half of the blackberry ( 21 of 36) and more than one-eighth of the strawberry (11 of 79) isolates were resistant to thiophanate-methyl, pyraclostrobin, boscalid, and fenhexamid. Most of the other 4SR isolates were resistant to thiophanate-methyl, pyraclostrobin, boscalid, and cyprodinil (14 of 37 for blackberry and 67 of 79 for strawberry; Tables 2 and 3).

To further characterize the rare occurrence of resistance to fludioxonil, $\mathrm{EC}_{50}$ was determined for the three resistant isolates. The $\mathrm{EC}_{50}$ value of isolate $\mathrm{CBa} 82$ was $0.16 \mu \mathrm{g} / \mathrm{ml}$ and was categorized as LR. This $\mathrm{EC}_{50}$ value was about 16-fold higher than the $\mathrm{EC}_{50}$ of the two sensitive isolates investigated $\left(\mathrm{EC}_{50}=0.01 \mu \mathrm{g} / \mathrm{ml}\right)$. The

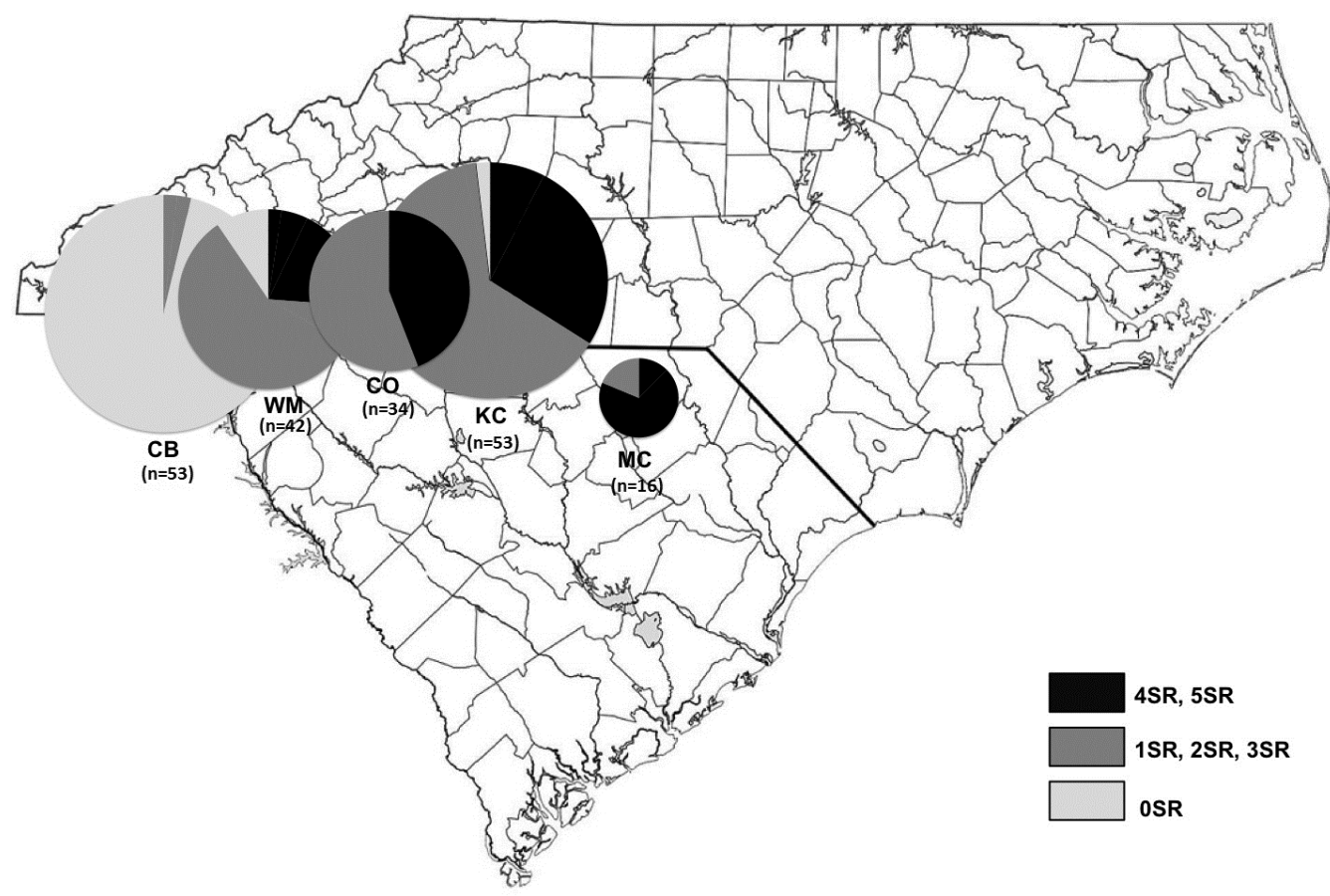

Fig. 1. Occurrence and prevalence of single resistances (SRs) in Botrytis cinerea isolates from blackberry farms in North and South Carolina. The circle diameter corresponds to the number of isolates tested in each location, which is also indicated in parentheses.

Table 3. Fungicide-resistant phenotypes in North and South Carolina strawberry fields

\begin{tabular}{|c|c|c|c|c|c|c|c|c|c|}
\hline \multicolumn{2}{|l|}{ Isolates } & \multirow[b]{2}{*}{$\mathbf{S R s}^{\mathbf{b}}$} & \multicolumn{7}{|c|}{ Phenotype $^{\mathrm{a}}$} \\
\hline Number & Percent & & $\mathbf{T m}$ & Py & Bo & Cy & $\mathrm{Fe}$ & Ip & Fl \\
\hline 65 & 30.4 & OSR & $\mathrm{S}$ & S & $S$ & $S$ & $\mathrm{~S}$ & $S$ & $\mathrm{~S}$ \\
\hline 4 & 1.9 & $1 \mathrm{SR}$ & $\mathbf{R}$ & $\mathrm{S}$ & $S$ & $\mathrm{~S}$ & $\mathrm{~S}$ & $S$ & $\mathrm{~S}$ \\
\hline 3 & 1.4 & $2 \mathrm{SR}$ & $\mathbf{R}$ & $\mathrm{S}$ & $\mathrm{S}$ & $\mathbf{R}$ & $\mathrm{S}$ & S & $\mathrm{S}$ \\
\hline 6 & 2.8 & $2 \mathrm{SR}$ & $\mathbf{R}$ & $\mathbf{R}$ & $S$ & $\mathrm{~S}$ & $\mathrm{~S}$ & S/LR & $\mathrm{S}$ \\
\hline 3 & 1.4 & $3 \mathrm{SR}$ & $\mathbf{R}$ & $\mathbf{R}$ & $\mathrm{S}$ & $\mathbf{R}$ & $\mathrm{S}$ & LR & $\mathrm{S}$ \\
\hline 26 & 12.1 & 3SR & $\mathbf{R}$ & $\mathbf{R}$ & $\mathbf{R}$ & S & $S$ & S/LR & $\mathrm{S}$ \\
\hline 11 & 5.1 & $4 \mathrm{SR}$ & $\mathbf{R}$ & $\mathbf{R}$ & $\mathbf{R}$ & $\mathrm{S}$ & $\mathbf{R}$ & $\mathrm{S} / \mathrm{LR}$ & $\mathrm{S}$ \\
\hline 1 & 0.5 & $4 \mathrm{SR}$ & $\mathbf{R}$ & $\mathbf{R}$ & $\mathbf{R}$ & $\mathrm{S}$ & $\mathrm{S}$ & $\mathbf{R}$ & $\mathrm{S}$ \\
\hline 67 & 31.3 & $4 \mathrm{SR}$ & $\mathbf{R}$ & $\mathbf{R}$ & $\mathbf{R}$ & $\mathbf{R}$ & $\mathrm{S}$ & S/LR & $\mathrm{S}$ \\
\hline 3 & 1.4 & $5 \mathrm{SR}$ & $\mathbf{R}$ & $\mathbf{R}$ & $\mathbf{R}$ & $\mathbf{R}$ & $\mathrm{S}$ & $\mathbf{R}$ & $\mathrm{S}$ \\
\hline 25 & 11.7 & 5SR & $\mathbf{R}$ & $\mathbf{R}$ & $\mathbf{R}$ & $\mathbf{R}$ & $\mathbf{R}$ & S/LR & S \\
\hline
\end{tabular}

${ }^{\mathrm{a}} \mathrm{Tm}=$ thiophanate methyl (methyl benzimidazole carbamate), Py = pyraclostrobin (quinone outside inhibitor), Bo = boscalid (succinate dehydrogenase inhibitor), $\mathrm{Cy}=$ cyprodinil (anilinopyrimidine), $\mathrm{Fe}=$ fenhexamid (hydroxyanilide), $\mathrm{Ip}=$ iprodione (dicarboximide), $\mathrm{Fl}=$ fludioxonil (phenylpyrrole); $\mathrm{S}=$ sensitive, $\mathrm{R}=$ resistant, $\mathrm{LR}=$ low resistant. Some letters are in bold for easier visualization.

${ }^{\mathrm{b}}$ Single resistances. 
other two isolates resistant to fludioxonil (KC25 and $\mathrm{KC} 33)$ had $\mathrm{EC}_{50}$ values of 0.324 and $0.383 \mu \mathrm{g} / \mathrm{ml}$, respectively, and were categorized as MR. All three isolates were also resistant to iprodione.

A model was introduced to test whether the distribution of susceptible and resistant phenotypes of isolates to a specific fungicide was random or biased. For the blackberry population, the results indicated that the subpopulation resistant to thiophanate-methyl was more likely to have evolved into a subpopulation resistant to thiophanate-methyl and pyraclostrobin $(P<0.05)$, which was more likely to have evolved into a subpopulation resistant to thiophanate-methyl, pyraclostrobin, and boscalid $(P<0.05)$. There was a bias toward developing strains resistant to thiophanate-methyl, pyraclostrobin, boscalid, and cyprodinil from the subpopulation resistant to thiophanate-methyl, pyraclostrobin, and boscalid $(P<$ 0.05). The low number of isolates $(n=2)$ resistant to all five chemical classes, including the HAs (fenhexamid), did not allow a standard test of significant differences in the $\mathrm{P}(\mathrm{R})$ values (Fig. 3A). A very similar pattern was observed for strawberry isolates (Fig. $3 \mathrm{~B})$. The 5SR phenotype characterized by resistance to thiophanate-methyl, pyraclostrobin, boscalid, cyprodinil, and fenhexamid was more likely to have derived from the subpopulation resistant to thiophanate-methyl, pyraclostrobin, boscalid, and cyprodinil $(P<0.05)$; the latter phenotype was more likely to have derived from the population resistant to thiophanate-methyl, pyraclostrobin, and boscalid $(P<0.05)$ and the isolates resistant to thiophanate-methyl and pyraclostrobin were more likely to have derived from the subpopulation resistant to thiophanate-methyl ( $P$ $<0.05$ ).

Detection of target gene mutations. To determine whether resistance was based on single-gene resistances, the presence or absence of mutations in genes encoding target proteins for fenhexamid, boscalid, pyraclostrobin, and thiophanate-methyl were investigated for all blackberry isolates with resistance phenotypes. All 23 blackberry isolates resistant to fenhexamid yielded a band approximately 586 bp in size when DNA was amplified with primers F412_F and F412_R. Sequence analysis revealed that 18 isolates possessed the F412S mutation, 4 had the F412I mutation, and 1 isolate $(\mathrm{KC} 52)$ had a new mutation, Y408H. Because the latter mutation had not been described before, the entire erg27 gene was sequenced and it was found that this gene also lacked amino acid P298 (Table 4). Three fenhexamid-sensitive isolates were randomly chosen and screened for mutations in the erg27 gene but none were found (data not shown). Primers IpBcBeg and IpBcEnd 2 amplified PCR fragments of about $950 \mathrm{bp}$ in length from the $s d h B$ gene of 24 blackberry isolates resistant to boscalid. Sequence analysis revealed nucleotide variations in resistant isolates but not the sensitive isolate from "CAC" to "TAC" in 8 isolates and "CGC" in 16 isolates. This mutation changed the amino acid at position 272 from histidine $(\mathrm{H})$ to tyrosine $(\mathrm{Y})$ or arginine (R) (Table 4). Primers Qo13ext and Qo14ext amplified the expected 560-bp product from the cytb gene of all 93 blackberry isolates resistant to pyraclostrobin and 1 isolate sensitive to pyraclostrobin. Enzyme Fnu4HI cut all amplicons from resistant isolates into two fragments of 318 and $242 \mathrm{bp}$ in length, indicating the presence of the G143A mutation (Table 4). The PCR product from the isolates sensitive to pyraclostrobin remained undigested. A PCR product of approximately $380 \mathrm{bp}$ in size was amplified from 137 blackberry isolates (136 resistant and 1 sensitive to thiophanate-methyl). The amplicon from 119 resistant blackberry isolates was successfully digested with ThaI, indicating the presence of the E198A mutation. The PCR product from the isolates sensitive to thiophanate-methyl remained undigested (data not shown). The remaining 17 blackberry isolates (all from location WM) resistant to thiophanate-methyl were not digestible with $T h a \mathrm{I}$ and, therefore, subjected to sequence analysis. The target gene revealed a nucleotide change from "GAG" to "GTG" at amino acid position 198, which changed glutamic acid to valine (E198V mutation; Table 4).

\section{Discussion}

Current models suggest that fungicide-resistant genotypes preexist at a low frequency (about $10^{-9}$ ) in a genetically diverse population $(20,46)$ prior to the introduction of a fungicide. In the absence of other constraints, one, two, or more independent forces such as pressure from single or multiple fungicides could select for single, dual, or greater levels of resistances. This is especially so if fungicides with different modes of action act on targets at different places in the genome. The phenotypic fungicide resistance patterns observed for populations from both crops (Tables 2 and 3) did not evolve randomly (Fig. 3A and B). Phenotypes resistant to multiple fungicides were more likely to have evolved from previously resistant subpopulations. The model suggests a stepwise accumulation of single resistance loci in $B$. cinerea populations from both

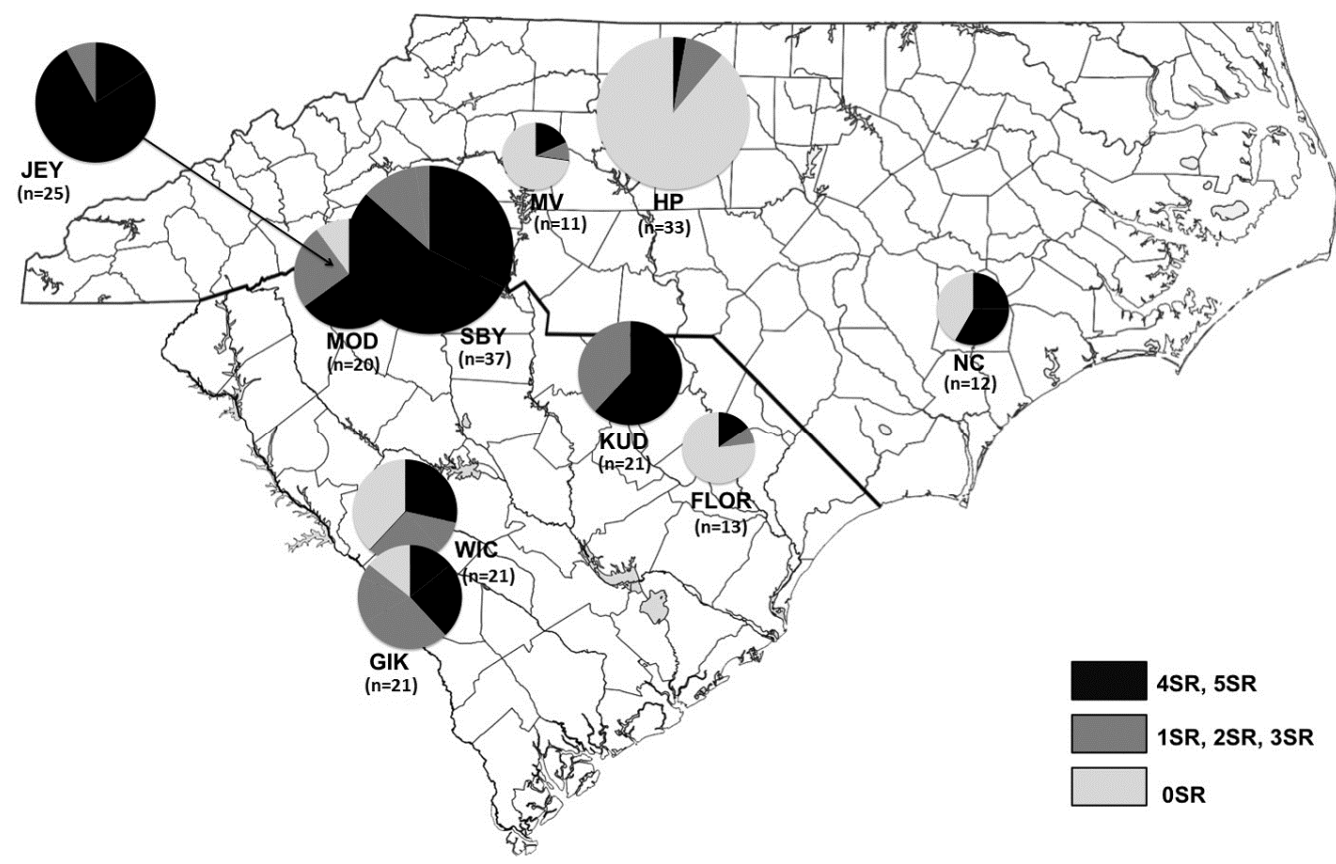

Fig. 2. Occurrence and prevalence of single resistance (SR) in Botrytis cinerea isolates from strawberry fields in North and South Carolina. The circle diameter corresponds to the number of isolates tested in each location, which is also indicated in parenthesis. The black arrow indicates the center of the circle for commercial field JEY. 
crops. Populations resistant to thiophanate-methyl gave rise to populations resistant to pyraclostrobin, which gave rise to populations resistant to boscalid, which gave rise to populations resistant to cyprodinil or fenhexamid. Fungicide pressure narrows the populations gene pool due to targeted selection of genotypes but evolution in the form of progressive changes in the gene pool causes the population to diversify and, therefore, allows emergence of new phenotypes (23). A simplified version of this standard population genetics theory describing stepwise selection, diversification, and accumulation of resistances is outlined in Figure 4. In this model, field applications of fungicides of a single chemical class followed by population recovery selects for genotypes resistant to fungicides of this chemical class and allows for diversification of the population. Diversification allows for emergence of strains with preexisting resistance to the next fungicide. The combined or alternated application of fungicides of the two chemical classes allows for the selection of preexisting genotypes with triple-fungicide resistance (Fig. 4).

Populations of $B$. cinerea from blackberry and strawberry fields in the Carolinas were resistant to multiple chemical classes of fungicides. Populations from conventionally sprayed fields (i.e., $\mathrm{KC}, \mathrm{MC}, \mathrm{CO}, \mathrm{MOD}, \mathrm{SBY}$, JEY, and KUD) had, with the exception of field SBY, a single-most prevalent resistance phenotype. These phenotypes consisted of resistance to thiophanate-methyl, pyraclostrobin, and boscalid and resistance to thiophanate-methyl, pyraclostrobin, boscalid, and iprodione in blackberry fields; and resistance to thiophanate-methyl, pyraclostrobin, and boscalid and resistance to thiophanate-methyl, pyraclostrobin, and cyprodinil in strawberry fields. This suggests that weekly applications of alternating fungicides, or mixtures of site-specific fungicides, selected for multifungicide-resistant strains. In contrast, the most prevalent phenotype for less frequently sprayed fields, such as WM (blackberry), MV, HP, and FLOR (strawberry) consisted of either only one (1SR) or no (0SR) single-resistant phenotypes. These data support common risk assessments that a reduction in the number of applications per season is an effective strategy to slow resistance development (7). Interestingly, multifungicide-resistant phenotypes existed at low frequency in the organic field, WIC, and many of the less-frequently sprayed fields (WM, MV, HP, and FLOR). This suggests that, if growers were to increase their use of fungicides, selection for multifungicide resistance could occur within a few sprays or a single season.

Resistance to four or five chemical classes (4SR and 5SR) was found in almost all blackberry and strawberry fields, raising the question of whether these phenotypes are a result of independent selection with small amounts of migration or successive expanding foci. Some locations were well over $100 \mathrm{~km}$ apart, suggesting that the multifungicide-resistant genotypes may have evolved independently from another, with little migration. Furthermore, recent evidence suggests that strawberry plug plants are a source of $B$. cinerea infections in plastic culture production systems (35). Therefore, B. cinerea multifungicide-resistant strains may have evolved at the nursery level and then been distributed to producers by way of planting material. This could also explain the presence of multifungicide-resistant strains in organic field WIC.

With only one exception, all fungicide-resistant isolates from both crops were resistant to MBC fungicide thiophanate-methyl. MBC fungicides were introduced in the 1970s and, therefore, used more often than the other six chemical classes, most of which were introduced much later. The combination of spray frequency, the

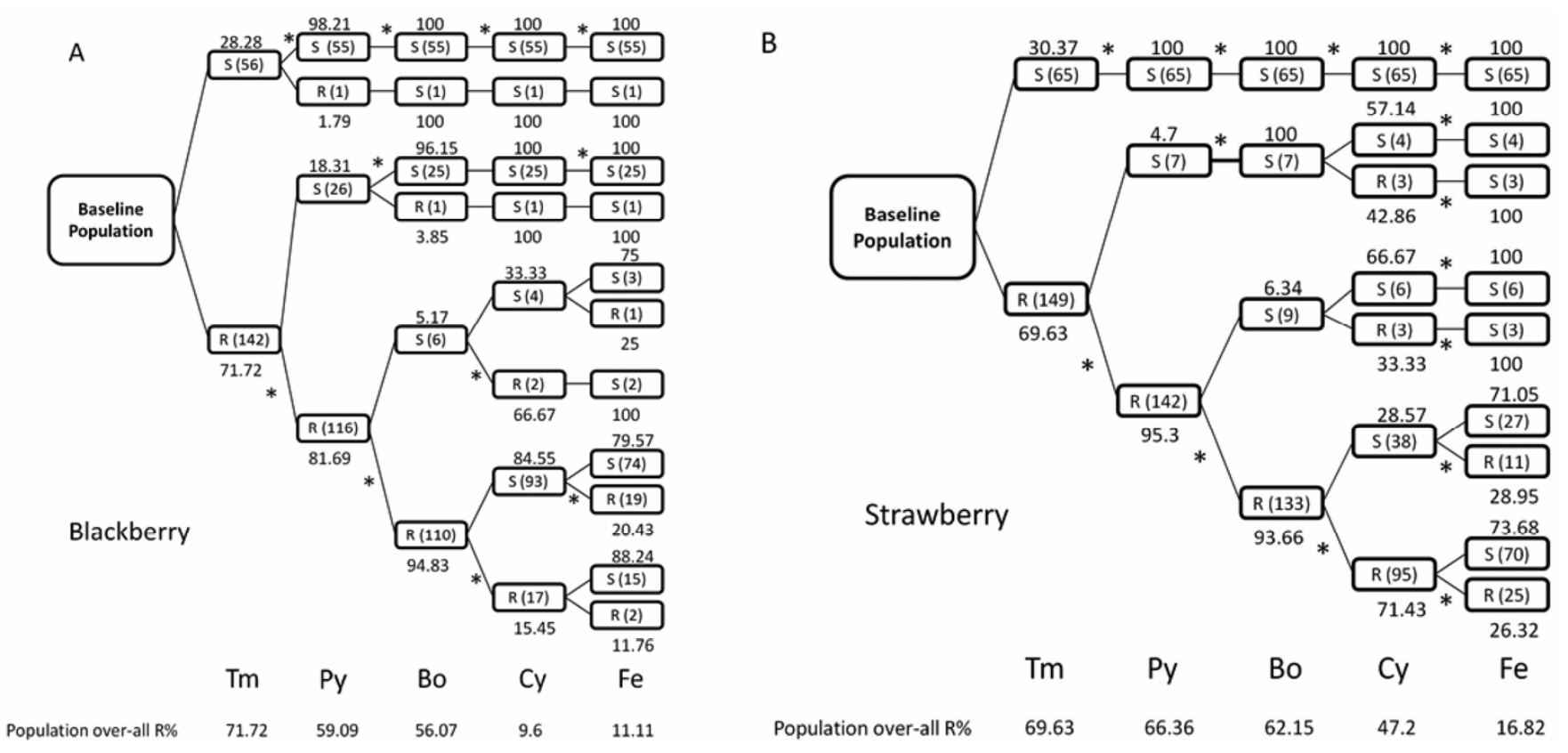

Fig. 3. Statistical model indicating bias toward the evolution of phenotypic fungicide resistance patterns in Botrytis cinerea from A, blackberry and B, strawberry fields. An asterisk (*) indicates that the probability of resistance $(\mathrm{R})$ in the subpopulation which derived from a previous $\mathrm{R}$ population is significantly higher $\left(\chi^{2}\right.$ test; $P$ value $\left.<0.05\right)$ than the probability of $R$ in the overall population for a certain fungicide. The number above or below the box indicates the ratio of that phenotype derived from the previous population. The numbers in parentheses in the box indicates the isolate number in that group. The bottom line indicates the fungicide $(\mathrm{Tm}=$ thiophanate-methyl, Py $=$ pyraclostrobin, $\mathrm{Bo}=$ boscalid, $\mathrm{Cy}=$ cyprodinil, and $\mathrm{Fe}=$ fenhexamid) in each selection stage and below is the resistant ratio in overall population to that fungicide.

Table 4. Mutations in target genes in blackberry isolates of Botrytis cinerea resistant to thiophanate-methyl, boscalid, pyraclostrobin, and fenhexamid

\begin{tabular}{|c|c|c|c|c|c|c|c|c|}
\hline & \multicolumn{8}{|c|}{ Amino acid substitutions in target proteins } \\
\hline & \multicolumn{2}{|c|}{$\beta$-tubulin $(n=136)$} & \multicolumn{2}{|c|}{$\operatorname{SdhB}(n=24)$} & \multirow{2}{*}{$\begin{array}{c}\text { Cytochrome b }(n=93) \\
\text { G143A }\end{array}$} & \multicolumn{3}{|c|}{$\operatorname{Erg} 27(n=23)$} \\
\hline & E198A & E198V & H272Y & H272R & & F412I & F412S & Y408H \& deletion P298 \\
\hline Number & 119 & 17 & 8 & 16 & 93 & 4 & 18 & 1 \\
\hline Percent & 87.5 & 12.5 & 33.3 & 66.7 & 100 & 17.4 & 78.3 & 4.3 \\
\hline
\end{tabular}


existence of naturally resistant strains in the field (45), the qualitative type of resistance $(6,12)$, and stability of the resistance $(10,40)$ may have probably caused a shift in the endemic population toward a dominant $\mathrm{MBC}$ resistance. Our data suggest that virtually all other resistance phenotypes derived from that dominant population. Dual resistance to QoIs and SDHIs has been reported in field strains from Europe $(4,30,34)$, the United States (27), and Asia (24). The delay in resistance development to AP fungicides may be because this product is mostly used in combination with fludioxonil, a compound that has proven quite resilient to resistance development (47). The delay in resistance to the HA fungicide fenhexamid may be the result of a documented reduced fitness of mutants with point mutations in the erg27 gene $(5,11)$. As for the DC fungicide iprodione, resistance was rare despite the fact that it had been registered for over 30 years. However, strawberry producers have not been using iprodione or used it rarely, due to its label-restricted use of one application prior to bloom. Although more applications are available to blackberry growers, the compound is not commonly used. In addition, multiple-genes could be involved in the development of resistance to DC fungicides, explaining the slower shift toward resistance (40).

Resistance to fludioxonil has only been described in isolates from grapevines in Germany (29), some apple isolates from apple in Washington State (47), and one isolate from strawberry in Virginia (13). The $\mathrm{EC}_{50}$ values for fludioxonil in resistant isolates were 0.04 to $1.5 \mu \mathrm{g} / \mathrm{ml}$, based on sampling location and assay method: Germany $(1.5 \mu \mathrm{g} / \mathrm{ml}$, germination assay), Washington $(0.04 \mu \mathrm{g} / \mathrm{ml}$, mycelia growth assay), and Virginia $(0.26 \mu \mathrm{g} / \mathrm{ml}$, germination assay). Isolates with resistance to fludioxonil possessed fitness penalties (47), which may explain the lack or low frequency of fludioxonil-resistant isolates in $B$. cinerea populations $(15,29)$. Both isolates from orchard $\mathrm{KC}$ that were resistant to fludioxonil were also resistant to thiophanate-methyl, pyraclostrobin, cyprodinil, and iprodione. Whether the fludioxonil-resistant strains described in this study are capable of causing significant yield loss following field applications of formulated product (i.e., Switch) is unclear.

Consistent with results published for our strawberry isolates $(14,17,22)$, resistance to thiophanate-methyl, pyraclostrobin, boscalid, and fenhexamid was, without exception, associated with target site mutations. The predominant mutation conferring resistance to fenhexamid in blackberry fields of the Carolinas was $\mathrm{F} 412 \mathrm{~S}$. This was consistent with our investigation of $B$. cinerea from strawberry fields in the Carolinas, where F412S was found in $80.6 \%$ of the isolates (22). In both studies, the F412I mutation was found rarely. The resistance phenotype associated with the $\mathrm{Y} 408 \mathrm{H}$

\section{Application of chemical class A}
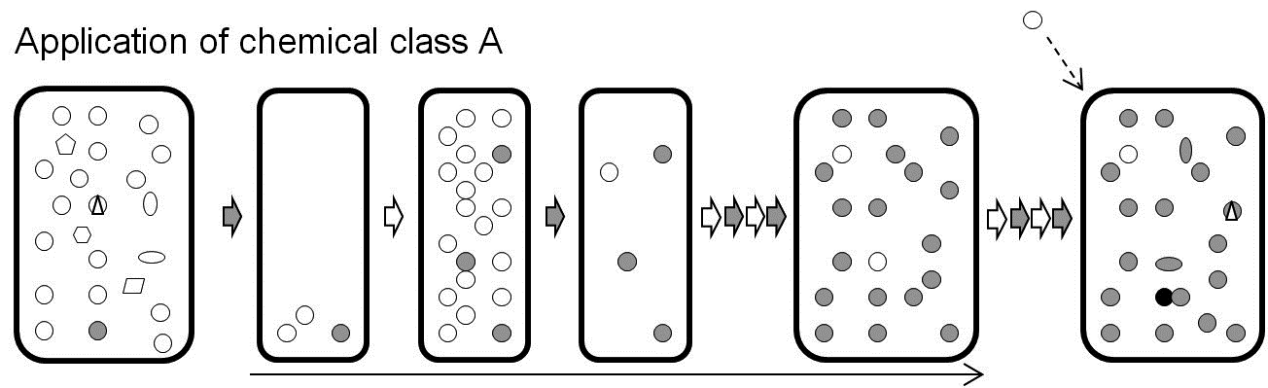

Selection and recovery

diversification

\section{Introduction of chemical class B}
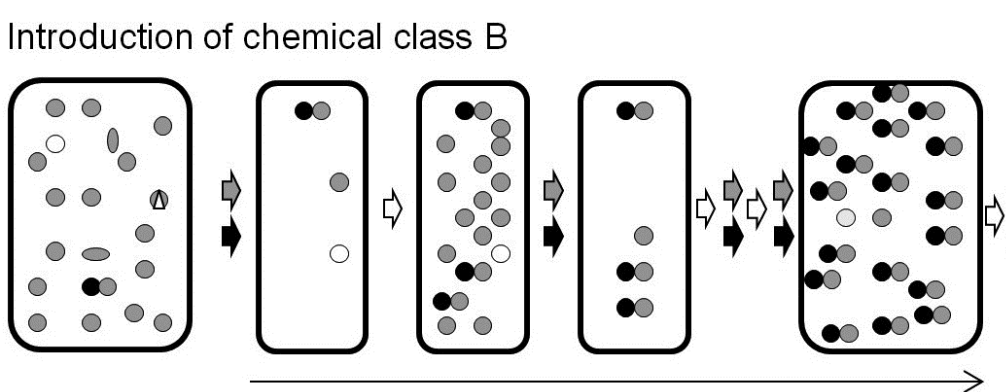

Selection and recovery

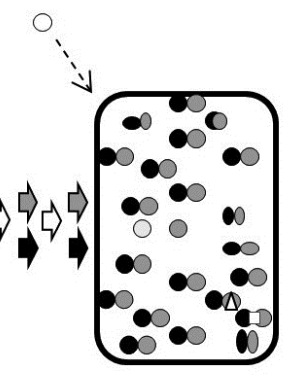

diversification

\section{Introduction of chemical class C}
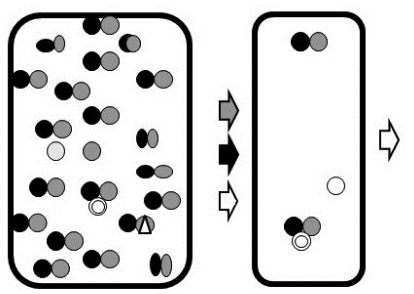

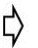

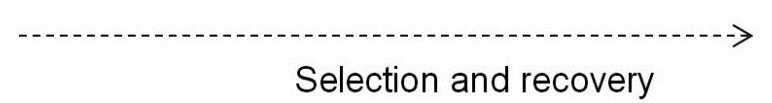

Fig. 4. Simplified representation of standard population genetics theory showing stepwise selection and accumulation of single resistances. A genotype (gray circle) with preexisting resistance to chemical class $\mathrm{A}$ is emerging from a genetically diverse population. The process of application of fungicides of chemical class $\mathrm{A}$ (gray arrow) and recovery (white arrow) selects for genotypes resistant to chemical class $A$ and allows for diversification of the population. The introduction of chemical class $B$ (black arrow) in rotation or mixture with $\mathrm{A}$ allows for the selection of preexisting phenotypes with dual resistance (combined gray and black circle). The single, empty circle outside the boxes indicates influx of genotypes from the outside. 
mutation combined with the $\mathrm{P} 298$ deletion is described here for the first time. Other mutations such as the T63I and F412C found at low frequencies in isolates from strawberry resistant to fenhexamid (22) were not found in the blackberry isolates we examined.

Although many mutations in the $s d h B$ gene such as H272L (30), P225L, and P225F (39) can cause resistance to SDHI fungicides, the predominant mutations in our collection were H272R and H272Y. Both genotypes were also the most prevalent found in our strawberry collection from the Carolinas (14). In both studies, the two mutations appeared at a ratio of 2 to 1 . This may indicate a slight fitness advantage of genotype $\mathrm{H} 272 \mathrm{R}$, as described previously (41), or may be evidence that the blackberry and strawberry populations share a common habitat and that there is an exchange of isolates among populations from different hosts. If this is true, it is more likely that the blackberry populations provide inoculum for the strawberry populations, because blackberry plants are perennials whereas most strawberry varieties in the Carolinas are grown as annuals in plastic culture-production systems.

The G143A mutation is the most frequently found and most powerful mutation in the cytochrome $b$ protein conferring resistance to QoI fungicides (18). In this study, all isolates resistant to pyraclostrobin analyzed had the G143A mutation. The same mutation also was responsible for resistance to pyraclostrobin in $B$. cinerea from strawberry (14). Other point mutations, such as G143R were found to contribute to resistance in Pyrenophora spp. but were not present in our studies (36). The sole presence of G143A in B. cinerea isolates resistant to QoI fungicides further validates the use of molecular techniques specific for the detection of the mutation in this pathogen.

In our study, $87.5 \%$ of the blackberry isolates resistant to thiophanate-methyl contained the E198A mutation, which makes this mutation the most prevalent one in $B$. cinerea from blackberry and strawberry in the Carolinas (17). In total, $12.5 \%$ of the blackberry isolates contained the E198V mutation in the $\beta$-tubulin gene. Variations at position 198 are commonly found in isolates highly resistant to thiophanate-methyl $(3,33)$ but the E198V mutation is rather rare. It was first reported in 2008 in isolates from various of hosts (i.e., cucumber, eggplant, tomato, and ornamental crops) in Japan (3) and, to the best of our knowledge, it has never been identified anywhere else.

In conclusion, this study shows that $B$. cinerea populations from blackberry and strawberry fields tend to have a single dominant fungicide resistance profile and that this profile is represented by multiple fungicides in fields frequently sprayed with site-specific fungicides. Multifungicide resistance likely evolved through stepwise selection and accumulation of resistance. The discovery of isolates resistant to fludioxonil and cyprodinil indicates that repeated application of Switch may eventually select for resistance to both fungicides. The continued use of site-specific fungicides, applied as mixtures or in alternation, will likely increase the prevalence of strains resistant to multiple fungicides. This assumption will decrease the growers' ability to control gray mold in the future. New strategies may have to be implemented to delay the selection of multifungicide resistance. These strategies may include a more frugal use of site-specific fungicides, a more frequent use of multisite inhibitors, and emphasis on clean plant sources and sanitation.

\section{Acknowledgments}

This material is based upon work supported by the CSREES/USDA, under project number SC-1000642. Dr. D. Fernández-Ortuño has received funding from the Marie Curie COFUND programme U-Mobility, co-financed by the University of Malaga, the European Commission FP7 under GA Number 246550, and Ministerio de Economía y Competitividad (COFUND2013-40259). We thank P. K. Bryson and F. P. Chen for technical support.

\section{Literature Cited}

1. Amiri, A., Heath, S. M., and Peres, N. A. 2013. Phenotypic characterization of multifungicide resistance in Botrytis cinerea isolates from strawberry fields in Florida. Plant Dis 97:393-401.

2. Anonymous. 2013. EPA United States Environmental Protection Agency. Online. http://iaspub.epa.gov/apex/pesticides/f?p=PPLS:1:2435105231739950
3. Banno, S., Fukumori, F., Ichiishi, A., Okada, K., Uekusa, H., Kimura, M. and Fujimura, M. 2008. Genotyping of benzimidazole-resistant and dicarboximide-resistant mutations in Botrytis cinerea using real-time polymerase chain reaction assays. Phytopathology 98:397-404.

4. Bardas, G. A., Veloukas, T., Koutita, O., and Karaoglanidis, G. S. 2010 Multiple resistance of Botrytis cinerea from kiwifruit to SDHIs, QoIs and fungicides of other chemical groups. Pest Manage. Sci. 66:967-973.

5. Billard, A., Fillinger, S., Leroux, P., Lachaise, H., Beffa, R., and Debieu, D. 2012. Strong resistance to the fungicide fenhexamid entails a fitness cost in Botrytis cinerea, as shown by comparisons of isogenic strains. Pest Manage. Sci. 68:684-691.

6. Brent, K. J. 1995. Fungicide Resistance in Crop Pathogens: How Can it be Managed? 1st ed. GCPF, Bristol, United Kingdom.

7. Brent, K. J., and Hollomon, D. W. 2007. Fungicide Resistance: The Assessment of Risk, 2nd ed. FRAC. Online publication. http://www.frac.info/frac/ publication/anhang/FRAC_Mono2_2007.pdf

8. Chi, M. H., Park, S. Y., and Lee, Y. H. 2009. A quick and safe method for fungal DNA extraction. Plant Pathol. J. 25:108-111.

9. Coley-Smith, J. R., Verhoeff, K., and Jarvis, W. R. 1995. The Biology of Botrytis. Academic Press, New York.

10. Decker, J. Acquired resistance to fungicides. 1976. Annu. Rev. Phytopathol. 14:405-428.

11. De Guido, M. A., De Miccolis Angelini, R. M., Pollastro, S., Santomauro, A., and Faretra, F. 2007. Selection and genetic analysis of laboratory mutants of Botryotinia fuckeliana resistant to fenhexamid. J. Plant Pathol. 89:203-210.

12. Deising, H. B., Reimann, S., and Pascholati, S. F. 2008. Mechanisms and significance of fungicide resistance. Braz. J. Microbiol. 39:286-295.

13. Fernández-Ortuño, D., Bryson, P. K., Grabke, A., and Schnabel, G. 2013 First report of fludioxonil resistance in Botrytis cinerea from a strawberry field in Virginia. Plant Dis. 97:848.

14. Fernández-Ortuño, D., Chen, F., and Schnabel, G. 2012. Resistance to pyraclostrobin and boscalid in Botrytis cinerea isolates from strawberry fields in the Carolinas. Plant Dis. 96:1198-1203.

15. Fernández-Ortuño, D., Chen, F., and Schnabel, G. 2013. Resistance to cyprodinil and lack of fludioxonil resistance in Botrytis cinerea isolates from strawberry in North and South Carolina. Plant Dis. 97:81-85.

16. Fernández-Ortuño, D., Li, X. P., Wang, F., and Schnabel, G. 2012. First report of gray mold of strawberry caused by Botrytis caroliniana in North Carolina. Plant Dis. 96:914.

17. Fernández-Ortuño, D., and Schnabel, G. 2012. First report of thiophanatemethyl resistance in Botrytis cinerea on strawberry from South Carolina. Plant Dis. 96:1700.

18. Fernández-Ortuño, D., Torés, J. A., de Vicente, A., and Pérez-García, A. 2008. Mechanisms of resistance of QoI fungicides in phytopathogenic fungi. Int. Microbiol. 11:1-9.

19. Fillinger, S., Leroux, P., Auclair, C., Barreau, C., Al Hajj, C., and Debieu, D. 2008. Genetic analysis of fenhexamid-resistant field isolates of the phytopathogenic fungus Botrytis cinerea. Antimicrob. Agents Chemother. 52:3933-3940.

20. Gisi, U., and Sierotzki, H. 2008. Molecular and genetic aspects of fungicide resistance in plant pathogens. Pages 52-61 in: Modern Fungicides and Antifungal Compounds V. H. W. Dehne, U. Gisi, K. H. Kuck, P. E. Russell, and H. Lyr, eds. Proc. 15th Int. Reinhardsbrunn Symp. Friedrichroda, Germany. BCPC, DPG, Braunschweig, Germany.

21. Grabke, A., Fernández-Ortuño, D., Amiri, A., Li, X. P., Peres, N. A., Smith, P., and Schnabel, G. Characterization of iprodione resistance in Botrytis cinerea from strawberry and blackberry. Phytopathology. 104:396-402.

22. Grabke, A., Fernández-Ortuño, D., and Schnabel, G. 2013. Fenhexamid resistance in Botrytis cinerea from strawberry fields in the Carolinas is associated with four target gene mutations. Plant Dis. 97:271-276.

23. Hartl, D. L., and Jones, E. W. 2000. Population genetics and evolution. Pages 727 in: Genetics: Analysis of Genes and Genomes, 5th ed. J. H. Hauck, M. Hill, T., Gleeson, and N. Healey, eds. Jones and Bartlett Publishers, Inc., Sudbury, MA

24. Ishii, H. 2012. Resistance to QoI and SDHI fungicides in Japan. Pages 223 in: Fungicide Resistance in Crop Protection: Risk and Management. T. S Thind, N. Farrar, A. Lainsbury, and F. Chippendale, eds. CABI, Wallingford, United Kingdom.

25. Jarvis, W. R. 1977. Botryotinia and Botrytis species. In: Taxonomy, Physiology and Pathogenicity, Vol. 15. Canadian Department of Agriculture, Ottawa, ON, Canada.

26. Jarvis, W. R. 1980. The biology of Botrytis. Pages 1-17 in: Taxonomy. Academic Press, London.

27. Kim, Y. K., and Xiao, C. L. 2011. Stability and fitness of pyraclostrobin and boscalid resistant phenotypes in field isolates of Botrytis cinerea from apple. Phytopathology 101:1385-1391.

28. Kretschmer, M., Leroch, M., Mosbach, A., Walker, A., Fillinger, S., Mernke, D., Schoonbeek, H., Pradier, J., Leroux, P., de Waard, M. A., and Hahn, M. 2009. Fungicide-driven evolution and molecular basis of multidrug resistance in the field populations of the grey mould fungus Botrytis cinerea. PLoS Pathog. 12:e1000696.

29. Leroch, M., Plesken, C., Weber, R. W. S., Kauff, F., Scalliet, G., and Hahn, M. 2013. Gray mold populations in German strawberry fields show multiple 
fungicide resistance and are dominated by a novel clade close to Botrytis cinerea. Appl. Environ. Microbiol. 79:159-167.

30. Leroux, P., Gredt, M., Leroch, M., and Walker, A. 2010. Exploring mechanisms of resistance to respiratory inhibitors in field strains of Botrytis cinerea, the causal agent of gray mold. Appl. Environ. Microbiol. 76:66156630.

31. Li, X. P., Fernández-Ortuño, D., Chai, W., Wang, F., and Schnabel, G. 2012. Identification and prevalence of Botrytis spp. from blackberry and strawberry fields of the Carolinas. Plant Dis. 96:1634-1637.

32. Li, X. P., Kerrigan, J., Chai, W., and Schnabel, G. 2012. Botrytis carolini$a n a$, a new species isolated from blackberry in South Carolina. Mycologia 104:650-658.

33. Luck, J. E., and Gillings, M. R. 1995. Rapid identification of benomyl resistant strains of Botrytis cinerea using the polymerase chain reaction. Mycol. Res. 99 12:1483-1488.

34. Markoglou, A. N., Malandrakis, A. A., Vitoratos, A. G., and Ziogas, B. N. 2006. Characterization of laboratory mutants of Botrytis cinerea resistant to QoI fungicides. Eur. Plant Pathol. 115:149-162.

35. Oliveira, M. S., Amiri, A., and Peres, N. A. 2013. The role of nursery plants as a potential source of inoculum for Botrytis cinerea and its impact on fungicide sensitivity. Am. Phytopathol. Soc. Annu. Meet. 218-P.

36. Sierotzki, H., Frey, R., Wullschleger, J., Palermo, S., Karlin, S., Godwin, J., and Gisi, U. 2007. Cytochrome $b$ gene sequence and structure of Pyrenophora teres and P. tritici-repentis and implications for QoI resistance. Pest Manage. Sci. 63:225-233.

37. Sosa-Alvarez, M., Madden, L. V., and Ellis, M. A. 1995. Effects of temperature and wetness duration on sporulation of Botrytis cinerea on strawberry leaf residues. Plant Dis. 79:609-615.

38. Staats, M., van Baarlen, P., and van Kan, J. A. L. 2005. Molecular phylogeny of the plant pathogenic genus Botrytis and the evolution of host spec- ificity. Mol. Biol. Evol. 22:333-346.

39. Stammler, G., Brix, H. D., Nave, B., Gold, R., and Schoefl, U. 2008. Studies on the biological performance of boscalid and its mode of action. Pages 45-51 in: Modern Fungicides and Antifungal Compounds V. H. W. Dehne, H. B. Deising, U. Gisi, K. H. Kuck, P. E. Russell, and H. Lyr, eds. 15th Int Reinhardsbrunn Symp. Friedrichroda, Germany.

40. Topolovec-Pintaric, S. 2011. Resistance to botryticides. Pages 1-44 in: Fungicides-Beneficial and Harmful Aspects. Thajuddin, eds. InTech. DOI: $10.5772 / 25823$

41. Veloukas, T., Leroch, M., Hahn, M., and Karaoglanidis, G. S. 2011. Detection and molecular characterization of boscalid-resistant Botrytis cinerea isolates from strawberry. Plant Dis. 95:1302-1307.

42. Walter, M., Boyd-Wilson, K. S. H., Perry, J. H., Elmer, P. A. G., and Frampton, C. M. 1999. Survival of Botrytis cinerea conidia on kiwifruit. Plant Pathol. 48:823-829.

43. Weber, R. W. S. 2011. Resistance of Botrytis cinerea to multiple fungicides in northern German small-fruit production. Plant Dis. 95:1263-1269.

44. Weber, R. W. S., and Hahn, M. 2011. A rapid and simple method for determining fungicide resistance in Botrytis. J. Plant Dis. Prot. 118:17-25.

45. Wolfe, M. S. 1982. Dynamics of the pathogen population in relation to fungicide resistance. Pages 139-148 in: Fungicide Resistance in Crop Protection. J. Dekker and S. G. Georgopoulos, eds. Centre for Agricultural Publishing and Documentation, Wageningen, The Netherlands.

46. Zhang, C., Hu, J., Wei, F., and Zhu, G. 2009. Evolution of resistance to different classes of fungicides in Botrytis cinerea from greenhouse vegetables in eastern China. Phytoparasitica 37:351-359.

47. Zhao, H., Kim, Y. K., Huang, L., and Xiao, C. L. 2010. Resistance to thiabendazole and baseline sensitivity to fludioxonil and pyrimethanil in Botrytis cinerea populations from apple and pear in Washington State. Postharvest Biol. Technol. 56:12-18. 